border of the tongue, which was slightly concave. It was now covered by a smooth layer of epithelium.

The operation took ten minutes, and the result was better than could have been expected after the application of the knife.

The second patient, a man, aged sixty, had a rodent ulcer on the cheek in front of the ear. Treated with $X$ rays and radium without permanent result. Last July the diathermy cautery was applied, and the edges and base of the ulcer were coagulated and sloughed off. Smooth, supple skin could now be felt covering the site of the former ulcer.

Archer Ryland.

\title{
NOTES AND QUERIES.
}

The Luetin Reaction for the Diagnosis of Syphilis.

Luetin is an extract of the killed cultures of several strains of the Treponema pallidum (Spirochæta pallida). The killing of the spirochætes for this purpose is effected by heating to $60^{\circ} \mathrm{C}$.; 0.5 per cent. trikresol is added as a preservative. The preparation is carefully tested to insure sterility, and is then placed in sterile ampuls or capillary syringes.

Method.-A site on the skin of the arm is cleansed and sterilised, and the luetin is injected into the skin as superficially as possible. The injection should be made between the layers of the skin, not under the skin. If properly done a small pale swelling is produced, which subsides in from ten to fifteen minutes.

Dosage.-The amount of luetin to ke injected for one test is 0.07 c.c.

The following phenomena indicate various types of positive reactions:

(a) The papular type consists of a large raised papule, reddish in colour and usually 7 to $10 \mathrm{~mm}$. ( $\frac{1}{4}$ to $\frac{1}{3} \mathrm{in}$.) in diameter, which makes its appearance in twenty-four to forty-eight hours. The papule may be surrounded by a diffused redness and show marked telangiectasis. 'The size of the papule and the induration may increase slowly during the following four to five days, after which it begins to recede and the colour gradually becomes dark brownish red. The induration gradually disappears within two weeks.

(b) The pustular type resembles the papular type until about the fourth or fifth day, when, instead of beginning to recede, the inflammatory processes increase in intensity, the surface of the papule becomes cedematous, with the formation of multiple miliary vesicles, and a central softening of the papule. Within the following twenty-four hours the papule is converted into a vesicle filled with serum, which later becomes purulent. The pustule soon ruptures and becomes covered with a crust that falls off within a few days, leaving a small induration, which is converted into a cicatrix after healing.

(c) In the torpid type the site of injection fades to an almost invisible point within three to four days, so that it may erroneously be considered a negative reaction. After ten days, or even longer, the spot suddenly begins to enlarge and goes through the same stages as seen in the pustular type.

Results. - Noguchi ${ }^{1}$ reports the results of the cutaneous reaction of 642 cases, comprising 315 syphilities, 77 parasyphilities and 250 controls.

In cases of primary and secondary syphilis which had had either insufficient treatment or no treatment at all, the reaction was negative except in a few instances in which the positive reaction was of the indurated papular type.

Most of the syphilitics in the secondary stage who had been treated with mercury followed by salvarsan, and who remained without symptoms for some months thereafter, gave strong positive reactions. In cases of tertiary and late hereditary syphilis there is usually an intense positive reaction. It is in these cases that the luetin test is of the greatest value. By this means it is possible to diagnose the disease in its diverse and obscure manifestations-a feature of great importance when it is desired to ascertain whether or not internal lesions are syphilitic. In this stage of the disease the Wassermann reaction is frequently negative, especially when patients have received recent treatment.

1 "Serum Diagnosis of Syphilis," by Hideyo Noguchi, M.D., M.Sc. J. B. Lippincott Company, Philadelphia. Third edition, 1912. Chapter on Luetin Reaction. 
In parasyphilitic cases the reactions were so variable that no definite decision could be made regarding their diagnostic value.

Dr. Noguchi and others have reported on various cases of tuberculosis, leprosy, pneumonia, typhoid fever, and various diseases other than syphilis, in which the test was applied, and in none of these did a positive reaction occur.

Based upon observations by various investigators since Noguchi, the value of the luetin test may be summarised as follows:

The luetin reaction is specific for syphilis.

It occurs most constantly and intensely during the tertiary and latent stages.

It is usually absent or very mild in the primary or secondary stages, although in these stages it may become positive after energetic treatment.

In infants with congenital syphilis it is less marked than in adults with congenital syphilis.

Repetition of the Luetin Test.-If a patient who gives a positive luetin reaction is tested again after a month's interval, the reaction takes the same form. If the test is made at intervals shorter than a month the reactions appear somewhat quicker, showing a shortening of the incubation period. The duration of the reaction is also shorter. When an injection of lnetin is made within one week of the positive reaction, only a mild reaction may take place, occurring within twenty-four hours and quickly fading away.

Effects of Treatment on the Luetin Test.-The luetin reaction is little affected by the usual intermittent mercurial treatment, with the exception, as previously stated, that in primary and secondary syphilis the reaction may become more positive under the mercurial or salvarsan treatment. Theoretically the test should become negative only when all of the spirochætes in the body of the patient have been killed. In practice, however, the negative luetin reaction should never be relied upon as an evidence that the patient is cured.

Noguchi states: "The absence of the clinical and serological signs of syphilis over a period of one year is certainly an encouraging aspect; but, considering the possibility of these signs being absent in some latent cases, one has a right to hesitate in pronouncing these cases as cured. It is in this connection that the luetin reaction may become a great aid in settling this important question. As already stated, the luetin reaction alone cannot decide the point ; but, combined with other means of diagnosis, it is bound to throw some light into this problem."

\section{NEW INSTRUMENTS.}

NASAL Forceps.

These are Luc's nasal forceps with the handle bent on the flat at an angle which permits the operator to keep the blades always in view.

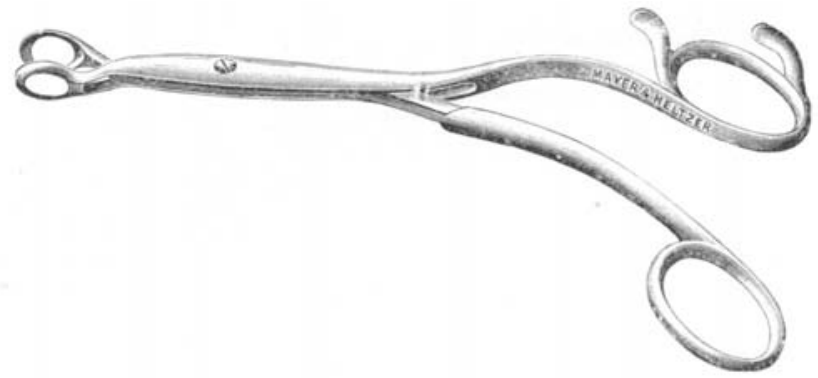

I have found them very useful in ordinary nasal work, like removing polypi and middle turbinals, as well as in the finer forceps manipulations in the submucous resection. The flanges on the handle provide additional holds for the fingers and add to the handiness of the instrument.

It has been made to my design by Messrs. Mayer and Meltzer.

Dan McKenzie. 


\section{MAYER \& MELTZER,}

Surgical Instrument Makers. ESTABLISHED OVER FIFTY YEARS.

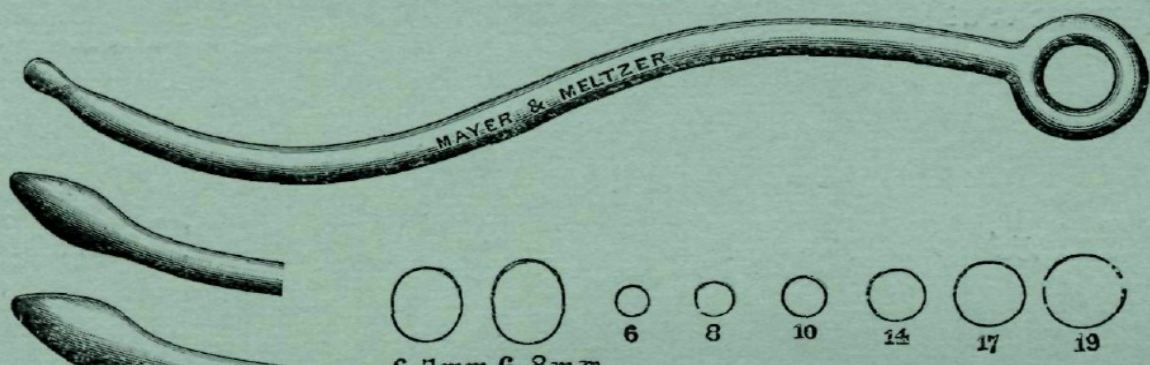

$6 \times 7 \mathrm{~mm} 6 \times 8 \mathrm{~mm}$

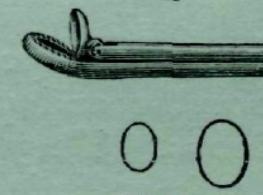

FULL SIZE
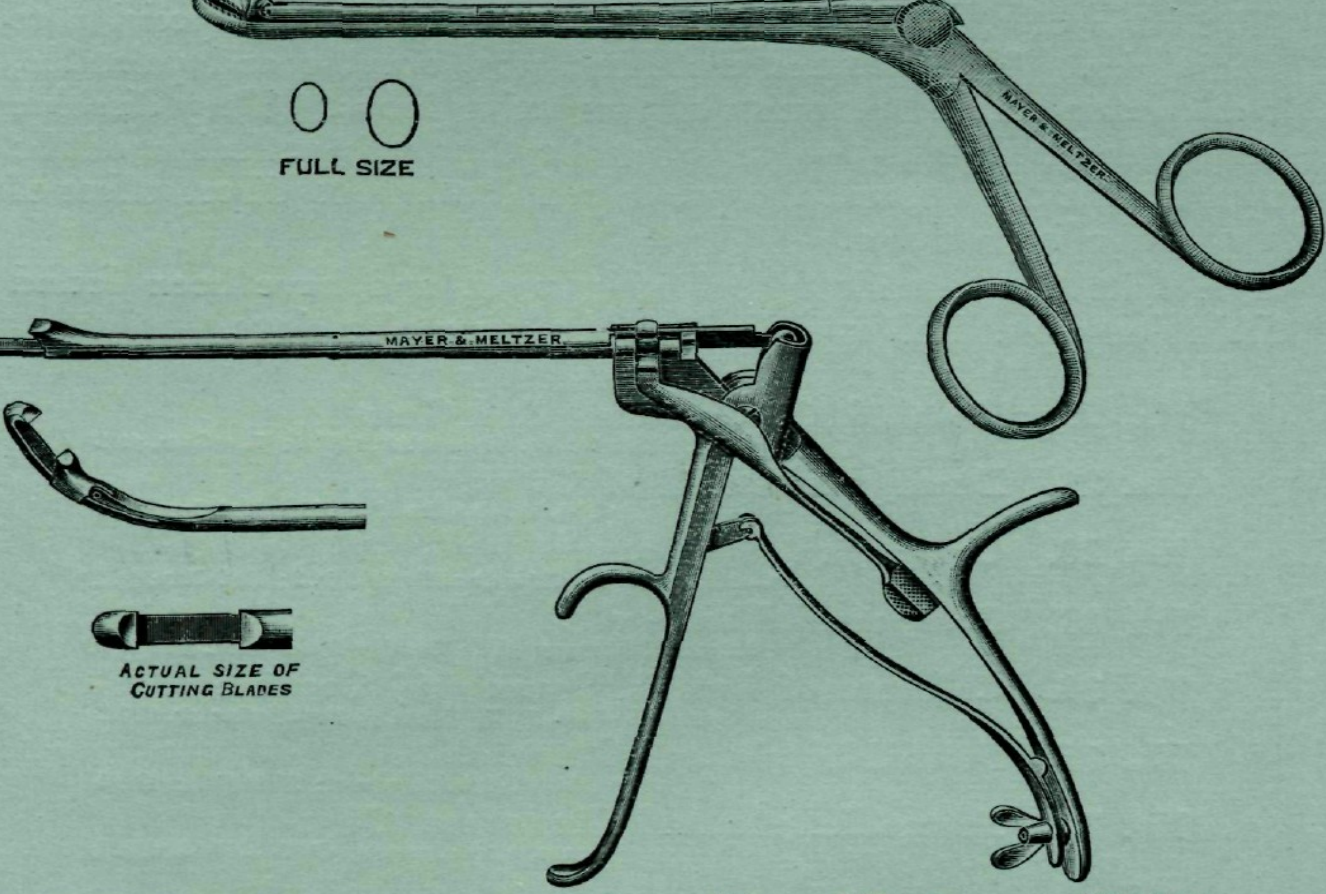

Instruments as used by Dr. Watson-Williams for the Intra-Nasal Operation for Frontal Sinus Suppuration.

(See JOURNAL OF LARYNGology, May, 1914.

Full Particulars on application.

MAYER \& MELTZER, 71, GREAT PORTLAND ST., LONDON. Branches: MELBOURNE; CAPE TOWN; JOHANNESBURG. 


\section{The "Allenburys" \\ (MEDICATED) \\ Throat Pastilles \\ Efficient

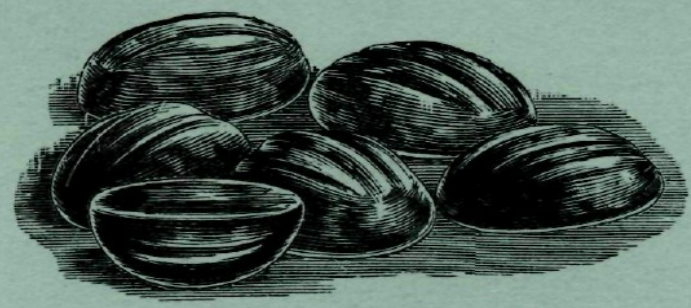 \\ Palatable}

The basis of the "Allenburys" Throat Pastilles is a special pâte de jujube. The pastilles are demulcent, soluble and palatable, and contain accurate amounts of pure active drugs. They dissolve slowly and uniformly, so ensuring the thorough suffusion of the mucous membrane, and the prolonged continuous direct effect of the active ingredients.

The following pastilles are largely used, and have been found from long practical experience to be very efficacious.

No. 9. Menthol, Cocaine and Red Gum

No. 23. Eucalyptus and Red Gum

No. 28. Compound Guaiacum

No. 29. Compound Rhatany

No. 38. Chlorate of Potash, Borax and Cocaine

Extract of Rhatany. gr. 2: Cocaine Hydrochlor., gr. 1/20th

Chlorate of Potash, gr. 2; Borax, gr. 1; Cocaine, gr. 1/20th

No. 75. Formaldehyde and Menthol

Formaldehyde, min. 1; Menthol, gr. 1/40th

No. 77. Formaldehyde and Cinnamon Oil

Formaldehyde, $\min .1$; Ol. Cinnamon, $\min . \frac{1}{2}$

1/- box of any variety, with detailed list, free to Medical Men in Great Britain.

IMPORTANT.-To ensure the supply of these active and reliable medicinal products, medical men should designate the

*ALLEINBUTYS" Pastilles in their prescriptions.

\section{Allen \& Hanburys Ltd. London}

NIAGARA FALLS, N.Y. TORONTO. BUENOS AIRES. DURBAN. SYDNEY. 